Revista de la red interuniversitaria de estudios sobre las literaturas rioplatenses contemporáneas en Francia

16 | 2017

Esnobismos

\title{
La maldición de las hadas
}

\section{Sebastián Urli}

\section{OpenEdition}

\section{Journals}

\section{Electronic version}

URL: http://journals.openedition.org/lirico/3776

DOI: 10.4000/lirico.3776

ISSN: 2262-8339

Publisher

Réseau interuniversitaire d'étude des littératures contemporaines du Río de la Plata

\section{Electronic reference}

Sebastián Urli, «La maldición de las hadas », Cuadernos LIRICO [En línea], 16 | 2017, Puesto en línea el 07 octubre 2017, consultado el 01 mayo 2019. URL : http://journals.openedition.org/lirico/3776 ; DOI : 10.4000/lirico.3776

This text was automatically generated on 1 May 2019.

\section{(c) (i) (9)}

Cuadernos LIRICO está distribuido bajo una Licencia Creative Commons Atribución-NoComercialSinDerivar 4.0 Internacional. 


\section{La maldición de las hadas}

\section{Sebastián Urli}

\section{REFERENCES}

Figueroa Estela. El hada que no invitaron. Obra poética reunida 1985-2016. Buenos Aires :

Bajolaluna, 2016. $224 \mathrm{p}$. 
La aparición de una poesía reunida es siempre un acontecimiento peculiar. Supone en primer lugar una continuidad, o una serie de continuidades : la sucesión de poemas y poemarios de diversas épocas reunidos en un solo volumen. Pero la obra reunida es también una distancia, no necesariamente una ruptura, frente a dicha continuidad, como si ese carácter ajeno ya estuviese en la obra pero solo se percibiera desde la temporalidad extraña, aunque condensada, del acto de reunir algo. En este sentido, el acto de reunir engendra su propia poética: no se trata de establecer continuidades temáticas o formales que de no contar con el "proyecto poético" no se podrían apreciar, sino más bien de subrayar la pausa que funda toda continuidad y las obsesiones que esa tensión genera.

2 El hada que no invitaron. Obra poética reunida es en este sentido una grata continuidad. En un solo volumen, Ediciones Bajolaluna ha reunido los tres poemarios previamente publicados por la autora: Máscaras sueltas (Centro de Publicaciones de la Universidad Nacional del Litoral, 1985), A capella (Ediciones delanada, 1991) y La forastera (Ediciones Recovecos, 2007) y ha agregado también un inédito, Profesión: sus labores. Como ya es costumbre en la editorial, al menos para la colección de poesía, se destacan la sobriedad de la tapa sin ilustraciones pero de un color rojo intenso, la tipografía usada, su tamaño, y una espaciada distribución de los versos que facilita la lectura.

3 Pero si la Obra poética reunida de Figueroa es una grata continuidad, lo es especialmente porque sus poemas, aun con la distancia específica entre cada poemario, encuentran en lo lateral y en lo oblicuo y, principalmente, en la pausa que todo abandono supone, su fuerza y sus posibilidades de decir. Cada libro, con la excepción del inédito, está conformado por diversas partes que subrayan algún aspecto particular de este proceso de continuidad y pausa : en Máscaras sueltas por ejemplo encontramos las secciones "Tiempo pasado", "La experiencia de los otros", "La experiencia de la muerte", "Tiempo presente" e "Instantáneas", zonas que, ya desde los títulos, se vinculan unas con otras, se enlazan y se separan, sin por eso dejar de trabajar el que quizás sea el eje principal de esta escritura : la renuncia como posibilidad. Porque como leemos en el primer poema de Máscaras sueltas , no es para hablar de sí que el yo escribe de la glicina ni es para hablar de la glicina que la compara con la lluvia :

Es para detener este momento nocturno:

la casa en calma

y los pensamientos que ennoblecidos velan

por un ordenamiento

que lo abarque todo. (11) 
Esta renuncia a un orden total no supone sin embargo la ausencia del evento en tanto horizonte posible, sino más bien la necesidad de detenerse y presentarse desde los desfasajes entre continuidad y pausa, entre presentación y representación, entre intimidad y exterioridad. Desde esta perspectiva no se trata en la poesía de Figueroa del hada que no fue invitada al evento ni de un evento que por definición excluyera a las hadas. Tampoco de una idealización de la ruina como única posibilidad de sentido. Se trata, más bien, de un hada que ha llegado tarde, un hada cuyo único don es, precisamente, la ausencia de todo atributo mágico, la melancolía de un deseo ajeno y, por eso, mucho más fuerte : más que el hada que no invitaron, el hada a la que invitaron a un evento donde no había nadie.

De allí entonces el "Y el camisón de seda pegado/ al cuerpo que no encuentra su sitio" de "Zumbido de una mosca" (39) o el retrato del ser querido muerto hace ya tres años, del poema "Pronto va a hacer" de Profesión : sus labores, retrato que el yo desea colgar y no cuelga, para agregar, como quien no quiere la cosa : "El clavo quedó allí/ sosteniendo tu ausencia" (158). O la confusión que produce la aparente tranquilidad del coro en "Tragedia griega" :

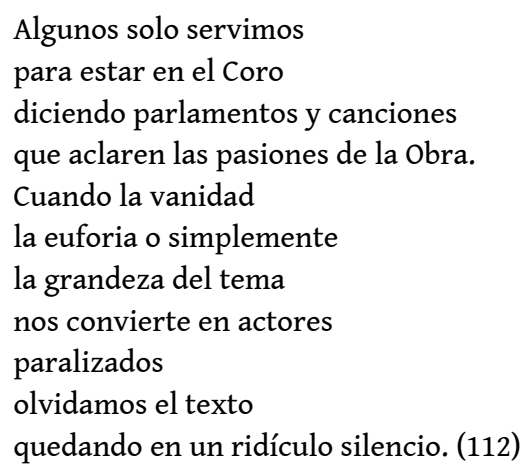

6 Poesía del ridículo, poesía del silencio, poesía de la ausencia. La de un coro de voces, nunca griego, nunca trágico, que dice exactamente lo que dice en su aparente tranquilidad, y por eso nos reconforta y por eso nos desespera ; como se sabe, lo aparente siempre es el mensaje y también su exceso, o el muro donde se posa el amor :

Todo amor nace

a partir de una pequeña confusión.

Nadie puede decir con certeza

si es el muro el que sostiene a su enamorada

o es la enamorada

la que sostiene el muro.

$\mathrm{Y}$ todo amor crece

a partir de pequeñas carencias :

La enamorada del muro no florece.

Tampoco el muro. ("La enamorada del muro", 93-94)

7 En esos versos finales queda cifrada una poética, sus alcances y sus límites, el movimiento que transforma sin necesidad de florecer, como el paso del tiempo, que la mirada de un perro o el crecimiento de las hijas ponen en entredicho: el paso del tiempo es inevitable, las ausencias son inevitables, pero lo inevitable permanece incólume quizá como el único aliado, como la única posibilidad que no cede y que sostiene a la amada, a su voz, al muro. Porque la fantasía del castillo no puede siquiera aguantar hasta la medianoche, porque las hadas madrinas no tienen varitas que realicen hechizos, en el peor de los casos tienen 
palabras y en el mejor, silencios o gestos minúsculos que son aun su más preciado alfabeto :

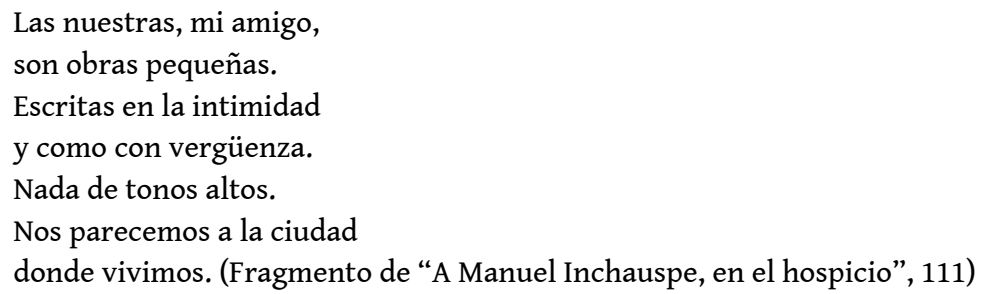

8 Pero hay que aceptar que en la poesía de Figueroa no se trata de volver extraña la intimidad sino todo lo contrario, hacer de lo extraño el epítome de lo íntimo, su fuerza pero nunca su límite. De allí que la descendencia de la mujer que escribe y del hombre vampiro sea, en "En la guardiana del hogar", dos pequeñas larvas de medusa que algunos domingos vuelven para comer en familia pero que siempre, no importa cuánto se intente detenerlas, "vuelven a irse/ por el río/ hacia el mar" (180). Por eso los poetas, dice un amigo en "Acompañando a mi hermana viuda", tenemos una rara condición : "como los moretones/ aparecemos después de los golpes", a lo que el yo responde con un gesto a medio camino entre una violencia elocuente y una inocencia fingida :

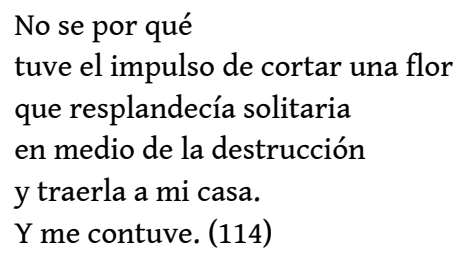

Poesía de las flores que no florecen, en muros que nunca sostienen amadas ; poesía de las medusas que vuelven solo para dejar en claro que deben irse, que ya se han ido, incluso antes de llegar ; poesía de los perros y de los gatos ; poesía de los amores correspondidos y las ausencias correspondidas (así es quizás el amor de un hada); poesía de las conversaciones íntimas en una ciudad pudorosa; poesía donde vivimos junto a la voz de Figueroa, voz que la poesía argentina debe volver a leer, y en la cual el evento principal es la intimidad de un coro, que como buen coro funda y critica su concepción del mundo, y canta siempre a destiempo porque solo así es posible cantar.

\section{AUTHORS}

\section{SEBASTIÁN URLI}

Bowdoin College 